\title{
Seasonal and temporal variation in scaled mass index of Black-capped Chickadees (Poecile atricapillus)
}

\author{
Emma J. NiP ${ }^{1, ~ *}$, Barbara Frei², and Kyle H. ElliotT ${ }^{2}$ \\ ${ }^{1}$ Department of Animal Biosciences, University of Guelph, Guelph, Ontario N1G 2W1 Canada \\ ${ }^{2}$ Department of Natural Resources Sciences, McGill University, Sainte-Anne-de-Bellevue, Quebec H9X 3V9 Canada \\ ${ }^{*}$ Corresponding author: emmajunkownip@gmail.com
}

Nip, E.J., B. Frei, and K.H. Elliott. 2018. Seasonal and temporal variation in scaled mass index of Black-capped Chickadees (Poecile atricapillus). Canadian Field-Naturalist 132(4): 368-377. https://doi.org/10.22621/cfn.v132i4.2015

\begin{abstract}
Avian body mass reflects a trade-off between risk of starvation and predation, and may vary with ambient temperature, age, and time of day. Seasonal variability in body mass is a common occurrence in northern temperate regions, including adaptive fattening. Previous evidence suggests that seasonal variability is less pronounced in tree-feeding bird species, as their food sources during winter are less limited and variable compared to ground-foraging species. We determined fat scores of tree-feeding Black-capped Chickadees (Poecile atricapillus) captured year-round between 2004 and $2015(n=4248)$ in southern Quebec, to test the relative strength of possible drivers of variability in chickadee body mass, including time, date, and year of capture, age, and temperature. First, we demonstrated that scaled mass index (SMI) was the body condition index, out of four possible indices tested, which most strongly correlated with fat scores measured in the field. We used SMI subsequently as our estimator of body condition to avoid observer effects associated with fat scores. Similar to other studies, time of capture significantly affected SMI, in which birds captured later were heavier, indicating that chickadees experience overnight weight loss and subsequent weight gain from foraging throughout the day. SMI was constant from April to November, then peaked in late winter, but was not influenced by daily temperature after accounting for month and year. SMI was not significantly affected by age. We concluded that adaptive fattening is an evolutionary response to risk of starvation in winter, rather than a proximal response to immediate ambient temperature.
\end{abstract}

Key words: Black-capped Chickadee; condition index; fat stores; scaled mass index; temperature; temporal; body mass

\section{Introduction}

Body mass varies greatly within bird species, often representing variation in lipid mass, and reflecting costs and benefits to high lipid stores (Lindstedt and Boyce 1985; Cresswell 1998). Higher lipid deposits may increase survival during periods of food shortage because fatter individuals have more endogenous energy stores (Thomas 2000; Krams et al. 2009; Ratikainen and Wright 2013). In winter, these energy stores may also act as buffers against cold temperatures, as birds expend more energy for thermoregulation, as well as against short winter days when reduced foraging increases the risk of starvation (Brodin et al. 2017; Da Silva et al. 2017). However, costs to higher body mass due to higher lipid deposits may include reduced takeoff ability and more time spent foraging to maintain a high body mass, both of which can increase chances of predation (Gosler et al. 1995; MacLeod et al. 2005, 2008; Rogers 2015). Alternatively, variation in lipid deposits may be stress-induced rather than adaptive; a lower average body mass may reflect low food availability rather than a fitness optimum (Ketterson et al. 1991; Kitaysky et al. 1999).

In northern temperate regions with large climate ranges, the effect of seasonality on body mass is especially pronounced (Haftorn 1992; Rogers 1995; Cooper 2007; Polo et al. 2007). The concept of adaptive winter fattening, in which small birds residing in cold habitats build up large fat reserves in response to low temperatures, has been widely studied (Haftorn 1989; Rogers 1995; Koenig et al. 2005; Merom et al. 2005) since its introduction by King and Farner in 1966. Weight gain in winter is caused by increased lipid deposits, which provide the metabolic fuel required to sustain an individual during winter fasts or food shortages (Lehikoinen 1987), as well as enlarged organs and muscles (Liu et al. 2008; Zheng et al. 2008, 2010; Liknes and Swanson 2011). Body mass tends to peak in midwinter and decline thereafter (Haftorn 1989). Lower body mass in spring and summer may be attributed to physiological stress during the breeding season or adaptive reduction in wing-loading to ease the labour of feeding nestlings (Freed 1981; Nagy et al. 2007). Other temporal factors that affect body mass include diurnal variation and migration (Winker et al. 1992; Cresswell 1998; Schaub and Jenni 2000).

Black-capped Chickadee (Poecile atricapillus), a tree-foraging species, overcomes the hardships of winter by caching its resources (Sherry and Vaccarino 1989), relying on micro-climates (Cooper and Swanson 1994), undergoing facultative diurnal hypothermia (Lewden et al. 2014), and increasing breast muscle size and enzymatic activity to improve shivering thermogenesis (Liknes and Swanson 2011). In ground-foraging birds, the trend of adaptive winter fattening holds true for several species, including juncos and sparrows (King 
and Farner 1966; Newton 1969; Rogers 1995), which those authors argued was exacerbated in ground-foragers because snowfall could limit access to groundborne resources, resulting in food shortages. In comparison, tree-foraging species have more predictable resources, and as such do not need to build up as large a fat supply (Rogers 1987; Rogers and Smith 1993; Graedel and Loveland 1995). The body mass of treefeeding species varies diurnally and seasonally, although the role of adaptive winter fattening is less prominent (Dawson and Marsh 1986; Silverin et al. 1989; Koivula et al. 1995; Cooper 2007).

There are several challenges associated with measuring size-corrected body mass in a non-destructive manner, such that ecologists have created various "condition indices" (Sears 1988; Redfern et al. 2000; Stevenson and Woods 2006; Jacobs et al. 2012). Some of the first indices involved using the ratio of body mass to a metric of body size, such as wing length. However, that method is often inaccurate because body size is seldom directly proportional to body mass (Peig and Green 2009). Calculating residuals from ordinary least squares regression (OLS) is one of the most popular methods, although several have argued that OLS violates key assumptions, leading to Type I and Type II errors (Garcia-Berthou 2001; Green 2001; Peig and Green 2009, 2010). To counter the flaws in OLS, Peig and Green (2009) developed the scaled mass index (SMI), which accounts for covariation between body size and body mass components during calculations by correcting body mass by a relative measure of body length.

Black-capped Chickadees are generally a well-studied species, particularly for food-storing behaviours (Sherry and Vaccarino 1989; Hitchcock and Sherry 1990; Smulders et al. 2004), social behaviour (Otter et al. 1998; Mennill et al. 2003), and vocal communication (Otter et al. 1997; Christie et al. 2004; Mennill and Ratcliffe 2004). The overall aim of our research was to provide additional information on fat mass variation at short- and long-time scales in Black-capped Chickadees using a 12-year data set and build on previous work that had focussed primarily on changes in muscle mass throughout the year (Swanson and Olmstead 1999; Swanson and Liknes 2006; Petit and Vézina 2014). Although we have direct estimates of visual lipid deposits within our dataset, those visual estimates are subjective and likely influenced by observer bias. Consequently, we elected to use a size-corrected mass index to estimate lipid levels in chickadees, with fat being the major cause of variation in body mass mediating a trade-off between higher reserves (longer fasting duration) and lower load (quicker predator escape). Thus, our first goal was to identify which condition index (body mass only, body mass/wing length, OLS, and SMI), is the most accurate predictor of lipids (as estimated by fat scores) in wild Black-capped Chickadees. We predicted that SMI would be the most reli- able predictor of fat scores, as SMI accounts for proportions relative to the individual and overcomes the flaws found in OLS. Our second goal was to determine the trends in size-corrected body mass using the available data, through the comparison of the most reliable condition index with various predictors, including mean temperature, time of day, and age. As chickadees are an overwintering species, we predicted that at longer time-scales (months) they undergo adaptive winter fattening. Specifically, we predicted that chickadees would have a higher relative body mass in winter and lower relative body mass in summer. We also predicted that at shorter time scales (hours) chickadees would be lightest in the morning after a night of fasting and would increase in relative body mass through the day due to foraging (Bednekoff and Krebs 1995; Cresswell 1998; Kullberg 1998). Lastly, we predicted that older chickadees, which are more experienced at finding food, and typically of higher rank with better access to food, would need smaller fat reserves (Daunt et al. 2007; Marchetti and Price 2008).

\section{Methods}

Data were collected in southern Quebec, Canada, at the McGill Bird Observatory from September 2004 until December 2015 as part of banding operations. The bird banding station is located adjacent to the Morgan Arboretum in Sainte-Anne-de-Bellevue, Quebec $\left(45.43^{\circ} \mathrm{N}, 73.94^{\circ} \mathrm{W}\right)$, in an open mixed deciduous/coniferous forest. Black-capped Chickadees were caught in a total of 16 mist nets to be weighed, measured, aged, sexed, and banded by trained individuals. Mist nets $(110 \mathrm{~d} / 2$ thread, $30 \mathrm{~mm}, 4$ shelf passerine nests from SpiderTech, Helsinki, Finland) measured $8-12 \mathrm{~m}$ in length, $3 \mathrm{~m}$ in height, with a mesh size of $30 \mathrm{~mm}$. During the spring and fall migration monitoring period, mist nets were open for five hours daily, starting 30 minutes before dawn except during rain. During the summer, chickadees were captured during MAPS (Monitoring Avian Productivity and Survivorship) operations, with mist nets open for six hours daily, starting 30 minutes before sunrise for each 10-day period (DeSante et al. 2016). During the non-standard winter banding, mist nets were employed opportunistically based on the weather conditions. Birds were collected from nets every 30 minutes, or more often during windy days. To reduce the impact on the birds, we did not net in the rain or in very poor conditions, and consequently we may be unable to detect the effect of extreme conditions. Further information about the banding process appears in Gahbauer and Hudson (2014).

The resulting dataset contains 4459 observations from 1866 individuals with outliers (outliers = body weight or wing chord $\pm 4 \mathrm{SD}$ ) removed over the 12year period. Outliers were likely due to human error during the recording of data. Black-capped Chickadees were aged by variation in their plumage. Not all individuals were reliably aged, depending on the time of 
year and the plumage characteristics, and in these cases the birds were recorded as unknowns (Pyle 1997). Chickadees were assigned "young" and "old" age classifications. Birds of unknown age were excluded from the analysis. Fall hatch-year and spring second-year birds were categorized as "young" and fall after hatchyear and spring after second-year were considered "old", for a total of 4248 observations that were of known age (Table 1). We did not determine the sex of the birds outside of the breeding season, so it was excluded from the analyses. Birds were weighed on an electronic balance (iBalance 700, My Weight Canada, Vancouver, British Columbia, Canada; accuracy of $0.1 \mathrm{~g}$ ), and wing length was measured with a ruler (accuracy of $1 \mathrm{~mm}$ ). Each bird was released shortly after the banding process was completed.

Subcutaneous fat was visually estimated using standard protocol and codes from the MAPS program (DeSante et al. 2016). As described by Rogers (1991: 351):

Each bird was held in the left hand, ventral side up, with the first two fingers of the left hand on the ventral (first finger) or dorsal (second finger) side of the neck. The first finger pressed against the base of the bill so that the bill pointed forward at approximately $45^{\circ}$ above the extended longitudinal axis of the bird. The first finger of the right hand was held lightly against the left side of the pectoral musculature while the right thumb lightly held the tail in its natural position. Birds were held gently to avoid injury, but firmly to avoid escape. With the bird held in the above position, the ventral contour feathers were blown aside and the subcutaneous fat observed in the two defined areas was classified as follows (after Nolan and Ketterson 1983). $0=$ no visible fat on abdomen (A) or in furcular depression (F). $1=\mathrm{F}<33 \%$ full, A $<50 \%$ covered. $2=$ F $33-66 \%$ full, A 50$100 \%$ covered but fat layer not even with pectoral region. $3=\mathrm{F}$ filled and fat flush with pectoral musculature, A completely covered, fat layer flush with pectoral musculature, thus neither $\mathrm{F}$ nor A bulging outward from pectoral musculature. $4=$ as in 3 with $\mathrm{F}$ or $\mathrm{A}$ bulging. 5 = both $\mathrm{F}$ and $\mathrm{A}$ bulging. Subcutaneous fat was recognized by its yellow or orange-yellow color, which contrasts with the dark red color of muscle.

Temperature data were collected from the SainteAnne-de-Bellevue climate station, located $1.5 \mathrm{~km}$ away from the banding sites $\left(45.25^{\circ} \mathrm{N}, 73.55^{\circ} \mathrm{W}\right)$, in SainteAnne-de-Bellevue, Quebec, Canada. As temperature data were occasionally missing from the local climate station, missing data were replaced using an equation (Sainte-Anne-de-Bellevue Temperature $=0.9987 \times$
TABLE 1. Number of captures of Black-capped Chickadees (Poecile atricapillus) across a 12-year period in southern Quebec, Canada. Only those used in the analyses are included ( $n$ $=4248$ ). Seasonal captures across all years were: 332 in late winter (January-March), 297 in spring (April-May), 542 in summer (June-August), 2277 in fall (September-October), and 800 in early winter (November-December).

\begin{tabular}{lc}
\hline \hline Year & Number of captures \\
\hline 2015 & 393 \\
2014 & 379 \\
2013 & 272 \\
2012 & 551 \\
2011 & 342 \\
2010 & 711 \\
2009 & 331 \\
2008 & 164 \\
2007 & 307 \\
2006 & 229 \\
2005 & 442 \\
2004 & 127 \\
\hline \hline
\end{tabular}

Airport Temperature $-0.2886, \mathrm{R}^{2}=0.99$ ) based on available data from the next closest climate station, at the Pierre Elliott Trudeau Airport (16 km away from banding sites; $\left.45.28^{\circ} \mathrm{N}, 73.45^{\circ} \mathrm{W}\right)$ in Montréal, Quebec, Canada (Environment Canada 2015).

\section{Comparing condition indices}

The regressions of the log-transformed body mass and wing length were taken to determine the slope of the regression (1.105), which was used later during the SMI calculations. We used a linear mixed-effects model (R package nlme; function lme; Pinheiro et al. 2016) to compare four different measurement methods: body mass only, body mass/wing length, OLS, and SMI, all of which act as predictors of fat. The data included only the individuals that had been captured at least three times over the duration of the study (2787 observations from 360 individuals) and using a linear mixed-effect model reduced pseudo-replications associated with recaptures. "Body mass only" used the actual weight (g) of each bird recorded by banders. We calculated the "weight/wing length" for each individual by dividing body mass (g) by wing length ( $\mathrm{mm})$. We obtained OLS values by calculating the residuals of body mass on wing length using the ordinary least squares regression. SMI was calculated using the formula

$$
\widehat{M}_{\imath}=M_{i}\left[\frac{L_{0}}{L_{i}}\right]^{b_{S M A}}
$$

where slope (1.105) of the body mass $\sim$ wing length regression acted as the scaling exponent, $\mathrm{b}_{\mathrm{SMA}}$, and $M_{i}$ and $L_{i}$ were the observed values, $L_{o}$ was the average length value for the entire population, and $\hat{M}_{i}$ was the predicted value for mass (Peig and Green 2009). Prior to using parametric statistics, we tested for normality in the data (Shapiro-Wilks; cut-off of W $>0.95$; R package stats; function shapiro.test; R Core Team 2015). 
We excluded fat scores of 4,5 , or 6 due to very small sample sizes, and because the average mass for 4,5 , and 6 were lower than the average fat score of 1 , thereby implying they were likely erroneous (i.e., chickadees are never fatter than a 3 ). The excluded values were distributed randomly throughout the year, and showed no pattern (and were rare), so excluding these values had no impact on our results. Because fat scores do not linearly translate into body mass, we first converted fat into body mass using the same model with fat score as a function of body mass (fixed effect) and individual (random effect), only including those individuals with at least three measurements. Setting a fat score of zero equal to $0 \mathrm{~g}$, based on the linear effects model, a fat score of one was equal to $0.14 \mathrm{~g}$, a fat score of 2 was equal to $0.39 \mathrm{~g}$, and a fat score of 3 was equal to $0.54 \mathrm{~g}$. Next, for each condition index, we calculated a linear mixed-effect model of fat score (converted to mass as above and with fat scores greater than 3 excluded) as a function of condition (fixed effect) and individual (random effect). We used Pearson's product-moment correlation test (R package stats; function cor; R Core Team 2015) to determine whether wing length is independent of body mass. We used a significance test with alpha set at 0.05 to determine which variables to include in the linear mixed-effect models.

\section{Predictors of variation in size-corrected body mass}

We calculated SMI for all 4248 observations for further analyses to test various predictors: temperature, age, and time of capture as time of day, and time of capture in month and years. We corrected for the time of day of capture by sunrise, using the formula: (time of capture - time of sunrise)/day length. Sunrise and day length data were collected from the National Research Council's sunrise database (National Research Council Canada 2016), using Montréal as the closest available city. Time of capture in month and year for all analyses were treated as categorical variables.

We first explored the relationships between the five possible drivers of SMI individually using univariate tests. For age (old versus young) we ran an unpaired, one-sample t-test ( $\mathrm{R}$ package stats; function t.test; $\mathrm{R}$ Core Team 2015). For temperature and relative time capture we used linear regression ( $\mathrm{R}$ package $\mathrm{lm}$; function t.test; R Core Team 2015). For month and year of capture we use an analysis of variance ( $\mathrm{R}$ package aov; function t.test; R Core Team 2015).
Next, we determined the relative strength of each driver, or biologically relevant combination of drivers, using mixed-effect linear models ( $\mathrm{R}$ package lme4; function lmer; Bates et al. 2017), with individual as a random effect. We framed our a priori candidate models to test the following hypotheses: (1) including all drivers (temporal, temperature, age) effects additively (global model), (2) average hourly temperature of the capture time alone (temperature model), (3) age of the individual at the time of capture alone (age model), (4) shorter time-scale temporal effects only as capture time of day alone (time of day model), (5) longer timescale temporal effects including additive effects of month and year of capture (month/year model), (6) longer time-scale temporal effects including additive and interaction effects of month and year of capture (interaction month/year model), (7) short and long timescale effects together additively (time of day/month/ year model), and (8) short and long time-scale effects together additively, and interaction of month and year of capture (interaction day/month/year model). We evaluated all nine models (including a null model with random effect of individual only) using Akaike Information Criterion adjusted for small sample sizes (AICc; Hurvich and Tsai 1989). Models were ranked according to the strength of support of each model, as determined by the difference in AICc between a given candidate model and the model with the lowest AICc ( $\triangle \mathrm{AICc}$; Anderson et al. 2001). AICc is a measure of model performance, which compares the maximumlikelihood estimates of the models, while penalizing for increasing complexity. Ranking was corroborated with the conditional $\mathrm{R}^{2}$ of the models ( $\mathrm{R}$ package piecewiseSEM; function sem.model.fits; Lefcheck 2016).

\section{Results}

\section{Comparison of condition indices}

SMI was the best predictor for subcutaneous fat measured in Black-capped Chickadees $\left(\mathrm{t}_{2423}=5.05 ; P<\right.$ 0.0001 ), followed by body mass only, body mass/wing length, and OLS (Table 2). Pearson's product-moment correlation test showed that wing length correlated positively with body mass $\left(\mathrm{t}_{2423}=43.7, P<0.0001, \mathrm{R}=\right.$ $0.55)$.

\section{Predictors of SMI in Black-capped Chickadees}

We found no significant difference between the SMI of young versus old Black-capped Chickadees (Figure 1a), with older birds having an average SMI of

TABLE 2. Simple regression statistical output for four different body condition indices as predictors of fat in Black-capped Chickadees (Poecile atricapillus) captured across a 12-year period in southern Quebec, Canada. Shown are the computed standard error, $t$-value, and $P$-value from a linear mixed effects model.

\begin{tabular}{lcrc}
\hline \hline Model & $\mathrm{df}$ & $t$-value & $P$-value \\
\hline Body mass only & 2423 & 4.04 & 0.0001 \\
Body mass/wing length & 2423 & -1.67 & 0.1000 \\
Ordinary least squares regression & 2423 & 1.59 & 0.1100 \\
Scaled mass index & 2423 & 5.05 & $<0.0001$ \\
\hline \hline
\end{tabular}


$10.90 \pm 0.62$ (SD) g, and young birds having an average of $10.92 \pm 0.60 \mathrm{~g}$. While both regressions of temperature and the relative time of capture to SMI were significant $(P<0.001)$, both model fits were low (Adjusted $\mathrm{R}^{2}=0.03,0.005$, respectively; Figure 1 ). Overall, SMI of Black-capped Chickadees decreased with increasing temperature (Figure 1b) and increased with relative time of capture (Figure 1c). SMI of Blackcapped Chickadees also significantly differed across the 12 months of the year, and the 12 years of the study (Figures 1d,e).

Of the nine models tested, the model that included all the temporal variables (time of day of capture, month, and year) explained the most variation in the SMI of Black-capped Chickadees (Table 3). The next best model (month/year of capture, as determined by AICc) was $>8$ AICc from the top model, thus it was significantly weaker than the top model (Anderson 2008). Thus, SMI variation in Black-capped Chickadees was primarily driven by temporal factors. We found a signif- icant and positive effect of the time of day, with birds increasing in SMI later in the day (Table 4). Chickadees varied in their SMI across the year, with birds later in the winter (February and March) having significantly greater SMI, and birds in the later summer and fall (July-November) having significantly lower SMI, compared to a January baseline (Table 4). SMI also varied across the 12-years of study, with certain years (e.g., 2013-2015) having chickadees with significantly higher SMI on average (Table 4).

\section{Discussion}

\section{SMI as an indicator of fat stores in Black-Capped Chickadees}

As predicted, SMI was the most accurate predictor of subcutaneous fat stores in Black-capped Chickadees, followed by body mass only, and body mass/wing length. OLS correlated the least to fat stores. Our results support our prediction that SMI, which corrects body mass by relative wing length, would be the most accu-

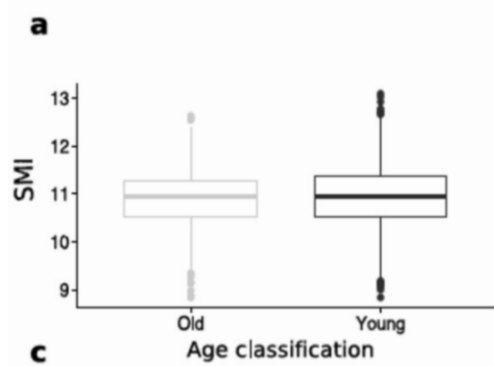

\section{b}
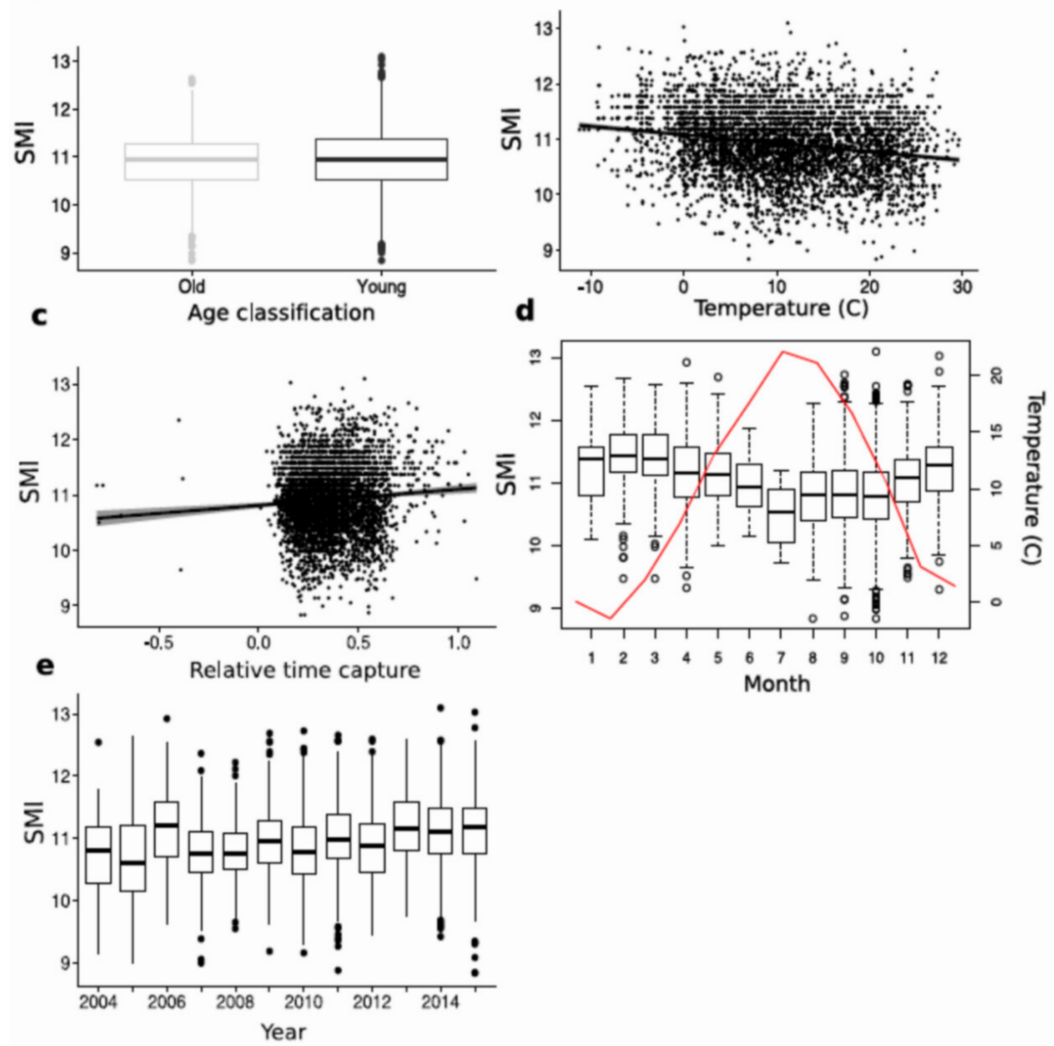

Figure 1. a. Boxplot of scaled mass index (SMI) of young and old Black-capped Chickadee (Poecile atricapillus); b. scatterplot of SMI versus mean temperature of day of capture for Black-capped Chickadees with linear regression line and $95 \%$ confident region in grey; c. scatterplot of SMI versus relative time of capture for Black-capped Chickadee; d. boxplots of SMI of Black-capped Chickadee across 12 months of the year, averaged across all years of study, with line graph of the average monthly temperature for each month across the study period in red; e. boxplots of mean SMI of Black-capped Chickadees across 12 years of the study. 
TABLE 3. Summary of rankings of candidate models using Akaike Information Criterion for small sample sizes (AICc) from linear mixed-effects models assessing the variation of scaled mass index (SMI) in Black-capped Chickadees (Poecile atricapillus) captured across a 12-year period in southern Quebec, Canada.

\begin{tabular}{lrrr}
\hline \hline Model & df & $\Delta$ AICc & Conditional R $^{2}$ \\
\hline Time of day/month/year & 26 & 0.0 & 0.67 \\
Month/year & 25 & 53.9 & 0.67 \\
Global & 113 & 151.7 & 0.69 \\
Interaction time of day/month/year & 111 & 182.7 & 0.69 \\
Interaction month/year & 110 & 232.2 & 0.68 \\
Temperature & 4 & 509.2 & 0.61 \\
Time of day & 4 & 577.3 & 0.62 \\
Age & 4 & 646.2 & 0.60 \\
Null & 3 & 663.7 & 0.59 \\
\hline \hline
\end{tabular}

TABlE 4. Parameter estimates from the time of day/month/year linear mixed-effects models assessing the variation of scaled mass index (SMI) in Black-capped Chickadees (Poecile atricapillus) captured across a 12-year period in southern Quebec, Canada. Model output for month effects are relative to January, and year effects relative to 2004. Significant parameter estimates are bolded.

\begin{tabular}{lccccc}
\hline \hline Model parameters & Estimates & SE & Df & $t$-value & $P$-value \\
\hline Time of capture & 0.36 & 0.04 & 3268 & 7.80 & $<0.001$ \\
Month of capture & & & & \\
February & 0.15 & 0.07 & 3423 & 2.07 & 0.040 \\
March & 0.15 & 0.06 & 3397 & 2.36 & 0.020 \\
April & -0.03 & 0.07 & 3410 & -0.49 & 0.630 \\
May & 0.06 & 0.07 & 3324 & 0.84 & 0.400 \\
June & -0.13 & 0.11 & 3763 & -1.12 & 0.260 \\
July & -0.75 & 0.09 & 3587 & -8.45 & $<0.001$ \\
August & -0.42 & 0.06 & 3492 & -6.83 & $<0.001$ \\
September & -0.37 & 0.06 & 3502 & -6.12 & $<0.001$ \\
October & -0.36 & 0.06 & 3561 & -6.16 & $<0.001$ \\
November & -0.21 & 0.06 & 3436 & -3.55 & $<0.001$ \\
December & -0.06 & 0.06 & 3323 & -0.89 & 0.370 \\
Year of capture & & & & \\
2005 & -0.08 & 0.05 & 3930 & -1.54 & 0.120 \\
$\mathbf{2 0 0 6}$ & 0.20 & 0.06 & 4036 & 3.10 & $<0.001$ \\
2007 & 0.02 & 0.06 & 4227 & 0.31 & 0.760 \\
2008 & 0.05 & 0.07 & 4200 & 0.67 & 0.510 \\
$\mathbf{2 0 0 9}$ & 0.14 & 0.06 & 4218 & 2.30 & 0.020 \\
2010 & -0.02 & 0.06 & 4161 & -0.41 & 0.690 \\
$\mathbf{2 0 1 1}$ & 0.13 & 0.06 & 4228 & 2.03 & 0.040 \\
2012 & 0.10 & 0.06 & 4149 & 1.72 & 0.090 \\
$\mathbf{2 0 1 3}$ & 0.28 & 0.07 & 4202 & 4.23 & $<0.001$ \\
$\mathbf{2 0 1 4}$ & 0.26 & 0.06 & 4123 & 4.05 & $<0.001$ \\
$\mathbf{2 0 1 5}$ & 0.18 & 0.07 & 4029 & 2.75 & 0.010 \\
\hline \hline
\end{tabular}

rate condition index out of the four methods for Blackcapped Chickadees. Similar to our findings, SMI was found to be a good predictor in another passerine species, European Starling (Sturnus vulgaris; Peig and Green 2009), while being a poor predictor of fat stores in non-passerine birds (Jacobs et al. 2012).

The use of OLS as a measure of body condition has been contested in recent years (Labocha and Hayes 2012). Peig and Green (2009) argued that OLS favours large individuals, as OLS measures absolute rather than relative fat (see Blackburn and Gaston 1997). Moreover, OLS may lead to Type I and Type II errors via violations of key assumptions - that the body size indicator (BSI) length (in this study: wing length) is independent of mass, and that BSI length does not have error (Green 2001). The result from the Pearson's product-moment correlation test demonstrates that our data violates the first assumption. Conversely, SchulteHostedde et al. (2005) compared OLS to major axis and reduced major axis regression and found OLS to be the suitable choice. Likewise, Jacobs et al. (2012) found that OLS outperformed SMI in predicting lipid stores in seabirds. While "body mass only" was the second most reliable option, we do not recommend using body mass alone as a predictor of fat in lieu of other methods, as it is necessary to account for relative proportions of each individual. 


\section{Temporal drivers as strongest predictors of SMI} variation in Black-Capped Chickadees

Temporal variables at both short time-scales (hours of the day) and long time-scales (months and years), were the strongest predictors of SMI variation in the Black-capped Chickadees in our study area. SMI was lowest in the morning and higher later in the day, which supports our prediction. Black-capped Chickadees spend several hours in the morning foraging to compensate for the energy lost the previous night. As hours go by, mass will increase until nightfall arrives again and body mass drops (Brittingham and Temple 1988). As shown in other studies, plasma triglycerides, indicative of fattening, are also high through mid-morning before dropping off in the afternoon, implying that most fattening occurs in the early morning (Mandin and Vézina 2012; Devost et al. 2014). Triglyceride levels, and therefore fattening, are highest in mid-winter (Mandin and Vézina 2012), consistent with our study.

SMI was, averaged across years, lowest from July to November, and highest in January to March suggesting that Black-capped Chickadees undergo adaptive winter fattening, although seasonal variation in body mass may be stress-induced or adaptive in other ways (Ketterson et al. 1991; Cresswell 1998; Kitaysky et al. 1999; Thomas 2000; Krams et al. 2009; Ratikainen and Wright 2013). Lower body mass in summer may be attributed to the stress of breeding season (Nagy et al. 2007), or reduction in energetic demands when flying to facilitate delivery of food to nestlings (Freed 1981; Croll et al. 1991). However, as we found low SMI from July-November, including the period well outside of the breeding season, we suggest that changes in SMI are mostly associated with winter fattening. Interestingly, we found that mean temperature did not significantly affect SMI in chickadees despite the seasonal variation in body mass. This discrepancy suggests that fat mass is programmed to increase during winter, rather than in response to immediate ambient temperature, although other factors, such as food availability and predation risk, may play important roles. These results are similar to other studies on tree-foraging species, including American Goldfinch (Spinus tristis; Dawson and Marsh 1986), Great Tit (Parus major; Silverin et al. 1989), and Willow Tit (Poecile montanus; Silverin et al. 1989; Koivula et al. 1995).

Age did not significantly affect SMI. In other species, weight generally increases with age due to growth and perhaps an improvement in feeding efficiency (Brooke 1978; Weimerskirch 1992). However, previous work on chickadees has demonstrated that birds of higher rank, which tend to be older (3.2 y compared to $1.5 \mathrm{y}$ for subordinates), are often lighter with lower fat scores, presumably because they have better access to food sources (Schubert et al. 2007). We expected younger birds, presumably of lower rank, to have a higher SMI to buffer against the risk of starvation, a threat which might be greater for younger birds, but our data do not reflect this.

Black-capped Chickadees are often the focus of foodcaching research, but there are few data on predictors and mechanisms behind body mass variation in this species. Although chickadees demonstrated winter fattening, it remains to be seen if temperature acts as a proximal or ultimate cause of weight gain/loss. The next step is to undertake experimental manipulations of temperature to determine how that influences avian body mass. Past studies have demonstrated that temperature, when measured over a longer period of time (e.g., several days to a month), acts as a proximal influence on metabolic rate in chickadees (Swanson and Olmstead 1999; Dubois et al. 2016). This current study used a much smaller window (time of capture) to assess the impact of temperature, and thus future research may wish to examine longer temporal variables as potential proximate factors.

\section{Author Contributions}

Writing - Original Draft: E.N.; Writing - Review \& Editing: K.E. and B.F.; Data Collection: B.F.; Formal Analysis: E.N., B.F., and K.E.

\section{Acknowledgements}

We thank Marcel Gahbauer, Simon Duval, Gay Gruner, Rodger Titman as well as all the banders and volunteers at the McGill Bird Observatory. Chris Solomon provided expert appraisal on the statistics, and three anonymous reviewers provided extensive helpful comments. Funding for this project was provided by Bird Protection Quebec, Bird Studies Canada, Environment Canada, and The John Hackney Foundation for the Noosphere.

\section{Literature Cited}

Anderson, D. 2008. Model Based Inference in the Life Sciences: a Primer on Evidence. Springer, New York, USA.

Anderson, D., W. Link, D. Johnson, and K.P. Burham. 2001. Suggestions for presenting the results of data analyses. Journal of Wildlife Management 65: 373-378. https: //doi.org/10.2307/3803088

Bates, D., M. Maechler, B. Bolker, S. Walker, R.H.B. Christensen, H. Singmann, B. Dai, G. Grothendieck, and P. Green. 2017. Linear mixed-effects models using 'Eigen' and S4. R package version 1.1-14. Accessed 2016-2017. https://cran.r-project.org/web/packages/lme4/ lme4.pdf.

Bednekoff, P.A., and J.R. Krebs. 1995. Great Tit fat reserves: effects of changing and unpredictable day length. Functional Ecology 9: 457-462. https://doi.org/10.2307/ 2390009

Blackburn, T.M., and K.J. Gaston. 1997. A critical assessment of the form of the interspecific relationship and body size in animals. Journal of Animal Ecology 66: 233-249. https://doi.org/10.2307/6025

Blem, C. 1973. Geographic variation in the bioenergetics of the House Sparrow. Ornithological Monographs 14: 96121. https://doi.org/10.2307/40168064 
Brittingham, M.C., and S.A. Temple. 1988. Impacts of supplemental feeding on survival rates of Black-capped Chickadees. Ecology 69: 581-589. https://doi.org/10.2307/194 1007

Brodin, A., J.Å. Nilsson, and A. Nord. 2017. Adaptive temperature regulation in the little bird in winter: predictions from a stochastic dynamic programming model. Oecologia 185: 43-54. https://doi.org/10.1007/s00442-017-3923-3

Brooke, M. de L. 1978. Weights and measurements of the Manx shearwater, Puffinus puffinus. Journal of Zoology 186: 359-374. https://doi.org/10.1111/j.1469-7998.1978. tb03925.x

Christie, P.J., D.J. Mennill, and L.M. Ratcliffe. 2004. Pitch shifts and song structure indicate male quality in the dawn chorus of black-capped chickadees. Behavioral Ecology and Sociobiology 55: 341-348. https://doi.org/ 10.1007/s00265-003-0711-3

Cooper, S.J. 2007. Daily and seasonal variation in body mass and visible fat in Mountain Chickadees and Juniper Titmice. Wilson Journal of Ornithology 119: 720-724. https:// doi.org/10.1676/06-183.1

Cooper, S.J., and D.L. Swanson. 1994. Seasonal acclimatization of thermoregulation in the Black-Capped Chickadee. Condor 96: 638-646. https://doi.org/10.2307/1369467

Cresswell, W. 1998. Diurnal and seasonal mass variation in blackbirds Turdus merula: consequences for mass-dependent predation risk. Journal of Animal Ecology 67: 78-90. https://doi.org/10.1046/j.1365-2656.1998.00174.x

Croll, D.A., A.J. Gaston, and D.G. Noble. 1991. Adaptive loss of mass in Thick-Billed Murres. Condor 92: 496-502. https://doi.org/10.2307/1368181

Da Silva A., D. Diez-Méndez, and B. Kempenaers. 2017. Effects of experimental night lighting on daily timing of winter foraging in common European songbirds. Journal of Avian Biology 48: 862-871. https://doi.org/10.1111/ jav.01232

Daunt, F., S. Wanless, M.P. Harris, L. Money, and P. Monaghan. 2007. Older and wiser: improvements in breeding success are linked to better foraging performance in European shags. Functional Ecology 21: 561-567. https://doi. org/10.1111/j.1365-2435.2007.01260.x

Dawson, W., and R. Marsh. 1986. Winter fattening in the American Goldfinch and the possible role of temperature in its regulation. Physiological Zoology 59: 357-368. https: //doi.org/10.1086/physzool.59.3.30156107

DeSante, D.F., K.M. Burton, P. Velez, D. Froehlich, D. Kaschube, and S. Albert. 2016. Maps manual 2016 protocol. Accessed 7 May 2016. http://www.birdpop.org/docs/ misc/MAPSManual16.pdf.

Devost, I., F. Hallot, M. Milbergue, M. Petit, and F. Vézina. 2014. Lipid metabolites as markers of fattening rate in a non-migratory passerine: effects of ambient temperature and individual variation. Comparative Biochemistry and Physiology Part A: Molecular \& Integrative Physiology 177: 18-26. https://doi.org/10.1016/j.cbpa.2014.07.014

Dubois, K., F. Hallot, and F. Vézina. 2016. Basal and maximal metabolic rates differ in their response to rapid temperature change among avian species. Journal of Comparative Physiology B 186: 919-935. https://doi.org/10.1007/ s00360-016-1001-5

Environment Canada. 2015. Daily and hourly data report for Ste-Anne-de-Bellevue, QC, and Pierre Elliott Trudeau Airport, QC. Accessed 5 May 2016. https://tinyurl.com/ y7eqvfvn.
Freed, L.A. 1981. Loss of mass in breeding wrens: stress or adaptation? Ecology 62: 1179-1186. https://doi.org/10.23 $07 / 1937282$

Gahbauer, M.A., and M.-A.R. Hudson. 2014. McGill bird observatory field protocol for migration monitoring program. Accessed 7 May 2016. https://tinyurl.com/y9knm3lh.

Garcia-Berthou, E. 2001. On the misuse of residuals in ecology: testing regression residuals vs. the analysis of covariance. Journal of Animal Ecology 70: 708-711. https://doi. org/10.1046/j.1365-2656.2001.00524.x

Gosler, A.G., J.J. Greenwood, and C. Perrins. 1995. Predation risk and the cost of being fat. Nature 377: 621-623. https://doi.org/10.1038/377621a0

Graedel, S.K., and R.E. Loveland. 1995. Seasonal and diurnal mass variation in Black-capped Chickadees and White-throated Sparrows. Wilson Bulletin 107: 723-727.

Green, A.J. 2001. Mass/length residuals: measures of body condition or generators of spurious results? Ecology 82: 1473-1483. https://doi.org/10.1890/0012-9658(2001)082 [1473:MLRMOB]2.0.CO;2

Haftorn, S. 1989. Seasonal and diurnal body weight variations in Titmice, based on analyses of individual birds. Wilson Bulletin 101: 217-235.

Haftorn, S. 1992. The diurnal body weight cycle in titmice Parus spp. Ornis Scandinavica 23: 435-443. https://doi. org/10.2307/3676674

Hitchcock, C.L., and D.F. Sherry. 1990. Long-term memory for cache sites in the black-capped chickadee. Animal Behaviour 40: 701-712. https://doi.org/10.1016/S0003-3472 (05)80699-2

Hurvich, C., and C.-L. Tsai. 1989. Regression and time series model selection in small samples. Biometrika 76: 297-307. https://doi.org/10.1093/biomet/76.2.297

Jacobs, S.R., K.H. Elliott, M.F. Guigueno, A.J. Gaston, P. Redman, J.R. Speakman, and J.M. Weber. 2012. Determining seabird body condition using nonlethal measures. Physiological and Biochemical Zoology 85: 85-95. https: //doi.org/10.1086/663832

Ketterson, E.D., V. Nolan, L. Wolf, C. Ziegenfus, A.M. Dufty, G.F. Ball, and T.S. Johnsen. 1991. Testosterone and avian life histories: the effect of experimentally elevated testosterone on corticosterone and body mass in dark-eyed juncos. Hormones and Behavior 25: 489-503. https://doi.org/10.1016/0018-506X(91)90016-B

King, J.R., and D.S. Farner. 1966. The adaptive role of winter fattening in the White-crowned Sparrow with comments on its regulation. American Naturalist 100: 403-418. https://doi.org/10.1086/282435

Kitaysky, A.S., J.C. Wingfield, and J.F. Piatt. 1999. Dynamics of food availability, body condition and physiological stress response in breeding Black-legged Kittiwakes. Functional Ecology 13: 577-584. https://doi.org/10.1046/j.13652435.1999.00352.x

Koenig, W.D., E.L. Walters, J.R. Walters, J.S. Kellam, K.G. Michalek, and M.S. Schrader. 2005. Seasonal body weight variation in five species of woodpeckers. Condor 107: 810-822. https://doi.org/10.1650/7718.1

Koivula, K., M. Orell, S. Rytkönen, and K. Lahti. 1995. Fatness, sex and dominance; seasonal and daily body mass changes in Willow Tits. Journal of Avian Biology 26: 209216. https://doi.org/10.2307/3677321

Krams, I., D. Cirule, V. Suraka, T. Krama, M.J. Rantala, and G. Ramey. 2009. Fattening strategies of wintering great tits support the optimal body mass hypothesis under conditions of extremely low ambient temperature. Func- 
tional Ecology 24: 172-177. https://doi.org/10.1111/j.13652435.2009.01628.x

Kullberg, C. 1998. Does diurnal variation in body mass affect take-off ability in wintering willow tits? Animal Behaviour 56: 227-233. https://doi.org/10.1006/anbe.1998.0765

Labocha, M.K., and J.P. Hayes. 2012. Morphometric indices of body condition in birds: a review. Journal of Ornithology 153: 1-22. https://doi.org/10.1007/s10336-011-0706-1

Lefcheck, J. 2016. Piecewise structural equation modeling. $\mathrm{R}$ package version 1.2.1. Accessed 2016-2017. https://cran. r-project.org/web/packages/piecewiseSEM/piecewiseSEM. pdf.

Lehikoinen, E. 1987. Seasonality of the daily weight cycle in wintering passerines and its consequences. Scandinavian Journal of Ornithology 18: 216-226. https://doi.org/10.23 07/3676769

Lewden, A., M. Petit, M. Milbergue, S. Orio, and F. Vézina. 2014. Evidence of facultative daytime hypothermia in a small passerine wintering at northern latitudes. Ibis 156 : 321-329. https://doi.org/10.1111/ibi.12142

Liknes, E.T., and D.L. Swanson. 2011. Phenotypic flexibility in passerine birds: seasonal variation of aerobic enzyme activities in skeletal muscle. Journal of Thermal Biology 36: 430-436. https://doi.org/10.1016/j.jtherbio.2011.07.011

Lima, S.L. 1986. Predation risk and unpredictable feeding conditions: determinants of body mass in birds. Ecology 67: 377-385. https://doi.org/10.2307/1938580

Lindstedt, S.L., and M.S. Boyce. 1985. Seasonality, fasting endurance, and body size in mammals. American Naturalist 125: 873-878. https://doi.org/10.1086/284385

Liu, J.-S., M. Li, and S.L. Shao. 2008. Seasonal changes in thermogenic properties of liver and muscle in tree sparrows Passer montanus. Acta Zoologica Sinica 54: 777784.

MacLeod, R., P. Barnett, J.A. Clark, and W. Cresswell. 2005. Body mass change strategies in blackbirds Turdus merula: the starvation-predation risk trade-off. Journal of Animal Ecology 74: 292-302. https://doi.org/10.1111/j. 1365-2656.2005.00923.x

MacLeod, R., J. Clark, and W. Cresswell. 2008. The starvation-predation risk trade-off, body mass and population status in the Common Starling Sturnus vulgaris. Ibis 150: 199-208. https://doi.org/10.1111/j.1474-919X.2008.00820.x

Mandin, C., and F. Vézina. 2012. Daily variation in markers of nutritional condition in wintering Black-capped Chickadees Poecile atricapillus. Ibis 154: 791-802. https://doi.org/ 10.1111/j.1474-919X.2012.01262.x

Marchetti, K., and T. Price. 2008. Differences in the foraging of juvenile and adult birds: the importance of developmental constraints. Biological Reviews 64: 51-70. https:// doi.org/10.1111/j.1469-185X.1989.tb00638.x

Mennill, D.J., S.M. Doucet, R. Montgomerie, and L.M. Ratcliffe. 2003. Achromatic color variation in black-capped chickadees, Poecile atricapilla: black and white signals of sex and rank. Behavioral Ecology and Sociobiology 53: 350-357. https://doi.org/10.1007/s00265-003-0581-8

Mennill, D.J., and L.M. Ratcliffe. 2004. Overlapping and matching in the song contests of black-capped chickadees. Animal Behaviour 67: 441-450. https://doi.org/10.1016/ j.anbehav.2003.04.010

Merom, K., S. Quader, and Y. Yom-Tov. 2005. The winter fattening model: a test at low latitude using the Clamorous Reed Warbler. Ibis 147: 680-687. https://doi.org/10.1111/ j.1474-919X.2005.00444.x
Nagy, L.R., D. Stanculescu, and R.T. Holmes. 2007. Mass loss by breeding female songbirds: food supplementation supports energetic stress hypothesis in black-throated blue warblers. Condor 109: 304-311. https://doi.org/10.1650/ 0010-5422(2007)109[304:MLBBFS]2.0.CO;2

National Research Council Canada. 2016. Sunrise/sunset Calculator. Accessed 17 September 2017. https://www.nrccnrc.gc.ca/eng/services/sunrise/index.html.

Newton, I. 1969. Winter fattening in the Bullfinch. Physiological Zoology 42: 96-107. https://doi.org/10.1086/physzool 42.1.30152470

Nolan, V., and E.D. Ketterson. 1983. An analysis of body mass, wing length, and visible fat deposits of Dark-Eyed Juncos wintering at different latitudes. The Wilson Bulletin 95: 603-620.

Otter, K., B. Chruszcz, and L. Ratcliffe. 1997. Honest advertisement and song output during the dawn chorus of blackcapped chickadees. Behavioral Ecology 8: 167-173. https:// doi.org/10.1093/beheco/8.2.167

Otter, K., L. Ratcliffe, D. Michaud, and P.T. Boag. 1998. Do female black-capped chickadees prefer high-ranking males as extra-pair partners? Behavioral Ecology and Sociobiology 43: 25-36. https://doi.org/10.1007/s00265 0050463

Peig, J., and A.J. Green. 2009. New perspectives for estimating body condition from mass/length data: the scaled mass index as an alternative method. Oikos 118: 1883-1891. https://doi.org/10.1111/j.1600-0706.2009.17643.x

Peig, J., and A.J. Green. 2010. The paradigm of body condition: a critical reappraisal of current methods based on mass and length. Functional Ecology 24: 1323-1332. https: //doi.org/10.1111/j.1365-2435.2010.01751.x

Petit, M., and F. Vézina. 2014. Phenotype manipulations confirm the role of pectoral muscle and haematocrit in avian maximal thermogenic capacity. Journal of Experimental Biology 217: 824-830. https://doi.org/10.1242/jeb. 095703

Pinheiro, J., D. Bates, S. DebRoy, D. Sarkar, and R Core Team. 2016. nlme: linear and nonlinear mixed effects models. R package version 3.1-124. Accessed 2016-2017. http://CRAN.R-project.org/package=nlme.

Polo, V., L.M. Carrascal, and N.B. Metcalfe. 2007. The effects of latitude and day length on fattening strategies of wintering coal tits Periparus ater (L.): a field study and aviary experiment. Journal of Animal Ecology 76: 866872. https://doi.org/10.1111/j.1365-2656.2007.01270.x

Pyle, P. 1997. Identification Guide to North American Birds. Part 1. Slate Creek Press, Bolinas, California, USA.

R Core Team. 2015. R: a language and environment for statistical computing. R Foundation for Statistical Computing, Vienna, Austria.

Ratikainen, I.I., and J. Wright. 2013. Adaptive management of body mass by Siberian jays. Animal Behaviour 85: 427434. https://doi.org/10.1016/j.anbehav.2012.12.002

Redfern, C.P.F., A.E.J. Slough, B. Dean, J.L. Brice, and P.H. Jones. 2000. Fat and body condition in migrating Redwings Turdus iliacus. Journal of Avian Biology 31: 197205. https://doi.org/10.1034/j.1600-048X.2000.310211.x

Rogers, C.M. 1987. Predation risk and fasting capacity: do wintering birds maintain optimal body mass? Ecology 68 : 1051-1061. https://doi.org/10.2307/1938377

Rogers, C.M. 1991. An evaluation of the method of estimating body fat in birds by quantifying visible subcutaneous fat. Journal of Field Ornithology 62: 349-356. 
Rogers, C.M. 1995. Experimental evidence for temperaturedependent winter lipid storage in the Dark-Eyed Junco (Junco hyemalis oreganus) and Song Sparrow (Melospiza melodia morphna). Physiological Zoology 68: 277-289. https://doi.org/10.1086/physzool.68.2.30166504

Rogers C.M. 2015. Testing optimal body mass theory: evidence for cost of fat in wintering birds. Ecosphere 6: 112. https://doi.org/10.1890/ES14-00317.1

Rogers, C.M., and J.N.M. Smith. 1993. Life-history theory in the nonbreeding period: trade-offs in avian fat reserves? Ecology 74: 419-426. https://doi.org/10.2307/1939303

Schaub, M., and L. Jenni. 2000. Body mass of six long-distance migrant passerine species along the autumn migration route. Journal of Ornithology 141: 441-460. https://doi.org/ 10.1007/BF01651574

Schubert, K.A., D.J. Mennill, S.M. Ramsay, K.A. Otter, P.T. Boag, and L.M. Ratcliffe. 2007. Variation in social rank acquisition influences lifetime reproductive success in black-capped chickadees. Biological Journal of the Linnean Society 90: 85-95. https://doi.org/10.1111/j.10958312.2007.00713.x

Schulte-Hostedde, A.I., B. Zinner, J.S. Millar, and G.J. Hickling. 2005. Restitution of mass-size residuals: validating body condition indices. Ecology 86: 155-163. https:// doi.org/10.1890/04-0232

Sears, J. 1988. Assessment of body condition in live birds; measurements of protein and fat reserves in the mute swan, Cygnus olor. Journal of Zoology 216: 295-308. https://doi. org/10.1111/j.1469-7998.1988.tb02431.x

Sherry, D.F., and A.L. Vaccarino. 1989. Hippocampus and memory for food caches in black-capped chickadees. Behavioral Neuroscience 103: 308-318. https://doi.org/10. 1037/0735-7044.103.2.308

Silverin, B., P.A. Viebke, J. Westin, and C.G. Scanes. 1989. Seasonal changes in body weight, fat depots, and plasma levels of thyroxine and growth hormone in free-living great tits (Parus major) and willow tits (P. montanus). General and Comparative Endocrinology 73: 404-416. https:// doi.org/10.1016/0016-6480(89)90198-6
Smulders, T.V., A.D. Sasson, and T.J. DeVoogd. 2004. Seasonal variation in hippocampal volume in a food-storing bird, the black-capped chickadee. Journal of Neurobiology 27: 15-25. https://doi.org/10.1002/neu.480270103

Stevenson, R.D., and W.A. Woods, Jr. 2006. Condition indices for conservation: new uses for evolving tools. Integrative and Comparative Biology 46: 527-538. https://doi. org/10.1093/icb/ic1052

Swanson, D.L., and E.T. Liknes. 2006. A comparative analysis of thermogenic capacity and cold tolerance in small birds. Journal of Experimental Biology 209: 466-474. https://doi.org/10.1242/jeb.02024

Swanson, D.L., and K.L. Olmstead. 1999. Evidence for a proximate influence of winter temperature on metabolism in passerine birds. Physiological and Biochemical Zoology 72: 566-575. https://doi.org/10.1086/316696

Thomas, R.J. 2000. Strategic diet regulation of body mass in European robins. Animal Behaviour 59: 787-791. https:// doi.org/10.1006/anbe.1999.1360

Weimerskirch, H. 1992. Reproductive effort in long-lived birds: age-specific patterns of condition, reproduction and survival in the wandering albatross. Oikos 64: 464-473. https://doi.org/10.2307/3545162

Winker, K., D.W. Warner, and A.R. Weisbrod. 1992. Daily mass gains among woodland migrants at an inland stopover site. Auk 109: 853-862. https://doi.org/10.2307/4088159

Zheng, W.-H., Y.-Y. Fang, X.-H. Jiang, G.-K. Zhang, and J.-S. Liu. 2010. Comparison of thermogenic character of liver and muscle in Chinese Bulbul Pycnonotus sinensis between summer and winter. Zoological Research 31: 319327. https://doi.org/10.3724/SP.J.1141.2010.03319

Zheng, W.-H., M. Li, J.-S. Liu, and S.L. Shao. 2008. Seasonal acclimatization of metabolism in Eurasian tree sparrows (Passer montanus). Comparative Biochemistry and Physiology 151A: 519-525. https://doi.org/10.1016/ j.cbpa.2008.07.009

Received 14 November 2017

Accepted 3 January 2019 